\title{
Kernos
}

Revue internationale et pluridisciplinaire de religion grecque antique

16 | 2003

Varia

\section{P. VOELKE, Un théâtre de la marge}

\section{Vinciane Pirenne-Delforge}

\section{(2) OpenEdition}

\section{Journals}

Édition électronique

URL : http://journals.openedition.org/kernos/845

DOI : $10.4000 /$ kernos. 845

ISSN : 2034-7871

Éditeur

Centre international d'étude de la religion grecque antique

Édition imprimée

Date de publication : 1 janvier 2003

Pagination : 372-373

ISSN : 0776-3824

Référence électronique

Vinciane Pirenne-Delforge, «P. voetKe, Un théâtre de la marge », Kernos [En ligne], 16 | 2003, mis en ligne le 14 avril 2011, consulté le 23 septembre 2020. URL : http://journals.openedition.org/kernos/ 845 ; DOI : https://doi.org/10.4000/kernos.845 
Au lecteur de faire son choix entre les deux éditions. De toute façon il sera excellent.

\section{Alain Moreau \\ (Université de Montpellier)}

Pierre Voelke, Un théatre de la marge. Aspects figuratifs et configurationnels du. drame satyrique dans l'Athènes classique, Bari, Levante Editori, 2001. 1 vol. 15,5× $21 \mathrm{~cm}, 471$ p., 28 fig. sur planches ("Le Rane». Collana di Studi e Testi, Studi - 31). ISBN : 88-7949-267-5.

Cet ouvrage est issu d'une thèse de doctorat soutenue à l'Université de Lausanne en 1999 , mais la thèse est clevenue un vrai livre. Se mesurant à un corpus difficile, essentiellement fragmentaire, l'A. nous propose un parcours d'une grande clarté, servi par un style aussi élégant que limpide, et une parfaite maitrise de la documentation, qu'il s'agisse des textes anciens, systématiquement traduits, ou des travaux, dont la bibliographie atteste l'abondance et les notes infrapaginales, l'utilisation effective et pertinente.

Après une brève insertion du propos dans la diachronie - l'histoire présumée du genre satyrique - et dans la réflexion des modernes - l'historiographie du genre en question -, l'A. aborde successivement les deux aspects évoqués dans le sous-titre : les figures constitutives du genre satyrique, d'une part, les « configurations » opérées par la mise en intrigue des drames, d'autre part. Ces deux dimensions d'analyse doivent servir à la constitution d'une définition du drame satyrique comme genre. Ce sont les aspects figuratifs qui occupent l'essentiel du propos. Articulée en dix chapitres sur un total de douze, cette analyse aborde successivement l'espace du drame satyrique, caractérisé par sa marginalité (chap. 2), la figure intermédiaire du satyre (humain/animal; enfant/adulte; masculin/féminin; humain/divin; servilité) (chap. 3), les satyres et leur relation à la musique et à ses instruments (chap. 4), à la danse et à ses rythmes (chap. 5), à la consommation d'un vin qui prend tout son sens confronté au lait, à la bière et à l'eau (chap. 6), à la sexualité (chap. 7) et au monde des athlètes (chap. 8). Ces satyres sont également mis en scène dans des contextes de découvertes ou de résolution d'énigmes, ce qui est moins souvent souligné (chap. 9). Enfin, ce sont les figures monstrueuses et leurs caractéristiques propres (axenia, asociabilité, impiété, démesure) qui sont envisagées, surtout dans leur face à face avec les satyres (chap. 10), et enfin les figures héroïques dans le déploiement très spécifique de leur activité « satyrique », en regard des tragédies (chap. 11). Ces dix chapitres fourmillent de développements susceptibles d'intéresser l'historien de la religion grecque, dans la mesure même où l'A. revendique la nécessité de contextualiser le drame satyrique et de concevoir les réseaux dans lesquels s'insèrent ces figures comme des constructions culturelles produites par «l'ensemble des pratiques signifiantes sociales, politiques, rituelles, discursives, iconographiques - d'un groupe humain donné » (p. 33). Contre l'habitude d'aller glaner ces fragments en ordre dispersé pour servir tel ou tel propos d'histoire religieuse ou d'analyse des mythes, nous disposons désormais d'un outil qui replace chaque fragment dans un cadre plus large, et autorise donc une exploitation plus pertinente des données effectivement disponibles. C'est le cas, entre beaucoup d'autres, du célèbre fragment du drame satyrique attribué à Critias ou à Euripide et qui met dans la bouche de Sisyphe un récit sur l'invention des dieux par un homme soucieux de mettre fin aux désordres à l'outre dans le monde (43 F 19 Snell).

Le dernier chapitre, consacré aux "aspects configurationnels», tente de pallier le caractère lacunaire du corpus en identifiant un certain nombre de thèmes qui permettent de saisir les articulations et les orientations de l'action dramatique, à défaut de pouvoir en reconstituer le développement. L'A. relève cinq thèmes, que leur récurrence conduit à considérer comme génériques : 1) la neutralisation d'une figure niant les valeurs de la civilisation, 2) la production d'objets, de figures et de phénomènes revêtant un caractère prodigieux et l'expérience qu'en font les satyres, 3) les marges comme espace d'expérimentation de leurs potentialités adultes pour les enfants divins et hérö̈ques, 4) les prétentions sexuelles des satyres déjouées par l'intervention d'un dieu ou d'un héros, 5) les prétentions des satyres à assumer des rôles qui leur sont étrangers comme, par exemple, celui d'époux. Ce même chapitre thématise ensuite un fil rouge du livre, à savoir les aspects dionysiaques du drame satyrique. S'il ne se perd pas dans la question épineuse 
des origines de la tragédie et du drame satyrique, l'A. est toutefois conscient des enjeux et prend indirectement position dans un débat relancé encore tout récemment ${ }^{1}$. Les relations aux rituels ménadiques et à d'éventuels rituels initiatiques, et le contexte non négligeable des Grandes Dionysies (et l'arrière-plan du Dionysos d'Éleuthères) sont autant d'éléments que l'A. met en résonance avec les données dionysiaques du drame satyrique. L'ancrage rituel en est fortement souligné, mais c'est sur la fonction du drame satyrique après la trilogie tragique que se referme le livre : la distanciation «permet au spectateur de revenir au culte et à la fête dionysiaque et, réciproquement, de se libérer des émotions suscitées par la représentation tragique » (p. 403). Rire, cohésion et identité culturelle peuvent ainsi « naître du spectacle de la transgression ».

Vinciane Pirenne-Delforge (FNRS - Université de Liège)

Aude Busine, Les Sept Sages de la Grèce antique. Transmission et utilisation d'un patrimoine légendaire d'Hérodote à Plutarque, Université libre de Bruxelles, Centre de recherche sur la Cité grecque / Paris, De Boccard, 2002. 1 vol. $16 \times 24 \mathrm{~cm}, 144 \mathrm{p}$. (Culture et cité, 1). ISBN : 2-7018-0148-6.

La syllogè des Sept sages a traversé tout le monde antique, jusqu'à d'ultimes avatars médiévaux. La bibliographie sur le sujet, dont l'A. souligne à juste titre le caractère obsolète, trouve dans ce petit ouvrage un rajeunissement bienvenu, servi par une méthode historique rigoureuse. Trois parties articulent la réflexion autour de l'émergence de la syllogè, de son contenu et sa diffusion, et de son utilisation par Plutarque. Sept chapitres numérotés en continu traversent les trois parties qui fournissent chacune une conclusion intermédiaire particulièrement commode.

L'analyse des textes d'Hérodote et de Platon conduit l'A. à supposer que l'association des Sept sages vit le jour au $\mathrm{vi}^{\mathrm{e}}$ siècle, quand Delphes chercha à fédérer les «sagesses locales » pour la plus grande gloire de son Apollon et pour l'affirmation de son statut de centre de la culture grecque. Le contexte aristocratique et civique des enjeux de l'affaire est adéquatement souligné, tout comme la réappropriation athénienne du thème des Sept sages dans le contexte anti-tyrannique de la cité du ve siècle. C'est au départ de ce modèle athénien qu'une sorte d'universalisation de la légende se fera jour par la suite, et l'A. suit pas à pas, au rythme des sources disponibles - parfois désespérément lacunaires -, les moindres traces des Sept sages à la période hellénistique. C'est le plus gros chapitre du livre, qui interroge notamment avec beaucoup de pertinence le statut du texte de Diogène Laërce comme «source» privilégiée pour cette période puisque bon nombre de références hellénistiques sont tirées de sa « compilation ». S'éloignant du contexte culturel archaïque qui l'avait vue naître, la syllogè deviendra toujours davantage une sorte de produit standard de la paideia, témoin et objet tout à la fois de la transmission du savoir et de la culture grecs.

En comparaison des pauvres lambeaux d'information qui informent sur la période hellénistique, l'œuvre de Plutarque occupe une place privilégiée dans le traitement de la syllogè puisqu'il a consacré tout un traité au banquet des Sept sages et que le thème apparaît aussi dans la Vie de Solon et le traité sur l'Epsilon de Delphes. "[L']intérêt [de Plutarque] pour la sagesse des Sept sages peut se resituer dans un vaste programme de restauration de l'image défaillante du sanctuaire de Delphes (p. 111) ». Toutefois, Plutarque n'exploitera nulle part un des thèmes récurrents de la syllogè, à savoir la dédicace à l'Apollon pythien de l'objet, coupe ou trépied, qui était destiné «au plus sage des Grecs ». La seule mention de cette dédicace apparaît dans la Vie de Solon $(4,2-7)$, et s'adresse à l'Apollon de Thèbes. Il est difficile de rendre véritablement compte de ces deux points de vue qui semblent contradictoires.

Tout au long du livre, c'est le terme de "légende " qui est utilisé pour désigner l'ensemble mouvant que constitue la réunion de ces personnages aux sentences laconiques. Bien que l'A. ne se prononce pas explicitement sur' ce point, le mot s'adapte très bien au

1 S. Scuelron, "Nothing to do with Dionysus': Tragedy misconceived as ritual", CQ 52 (2002), p. 102-137. 